\title{
Effect of Temperature on Plasma-Assisted Catalytic Cracking of Palm Oil into Biofuels
}

\author{
I. Istadi*, Teguh Riyanto, Luqman Buchori, Didi Dwi Anggoro, Roni Ade \\ Saputra, Theobroma Guntur Muhamad
}

Department of Chemical Engineering, Faculty of Engineering, Diponegoro University, Indonesia

\begin{abstract}
Plasma-assisted catalytic cracking is an attractive method for producing biofuels from vegetable oil. This paper studied the effect of reactor temperature on the performance of plasma-assisted catalytic cracking of palm oil into biofuels. The cracking process was conducted in a Dielectric Barrier Discharge (DBD)-type plasma reactor with the presence of spent RFCC catalyst. The reactor temperature was varied at 400,450 , and $500{ }^{\circ} \mathrm{C}$. The liquid fuel product was analyzed using a gas chromatography-mass spectrometry (GC-MS) to determine the compositions. Result showed that the presence of plasma and catalytic role can enhance the reactor performance so that the selectivity of the short-chain hydrocarbon produced increases. The selectivity of gasoline, kerosene, and diesel range fuels over the plasma-catalytic reactor were $16.43 \%, 52.74 \%$ and $21.25 \%$, respectively, while the selectivity of gasoline, kerosene and diesel range fuels over a conventional fixed bed reactor was $12.07 \%, 39.07 \%$, and $45.11 \%$, respectively. The increasing reactor temperature led to enhanced catalytic role of cracking reaction, particularly directing the reaction to the shorter hydrocarbon range. The reactor temperature dependence on the liquid product components distribution over the plasma-catalytic reactor was also studied. The aromatic and oxygenated compounds increased with the reactor temperature. C2020. CBIORE-IJRED. All rights reserved
\end{abstract}

Keywords: biofuels; plasma-assisted catalytic cracking; palm oil; spent RFCC catalyst

Article History: Received: Oct 30,2019; Revised: January 8, 2020; Accepted: February 4, 2020; Available online: February 15, 2020

How to Cite This Article: Istadi, I., Riyanto, T., Buchori, L., Anggoro, D.D., Saputra, R.A., and Muhamad, T.G. (2020) Effect of Temperature on Plasma-Assisted Catalytic Cracking of Palm Oil into Biofuels. International Journal of Renewable Energy Development, 9(1), 107-112. https://doi.org/10.14710/ijred.9.1.107-112

\section{Introduction}

Energy demand increases as economic growth, population growth, energy cost, and government policy. In line with the increase in national energy demand, petroleum demand is expected to increase. On the other hand, petroleum reserves are depleting, because it is a nonrenewable/limited energy resource. Therefore, renewable alternative energy is needed to supply energy demands. One alternative energy, which is potential to be developed, is biofuel. The biofuel is a renewable energy, because it is produced from biomass through chemical conversion. Biofuel can be a liquid or gas fuel containing short-chain and long-chain hydrocarbons which can be fractionated into various types of derivative fuels, such as: gasoline, kerosene, diesel, and other long chain hydrocarbons (Giampietro et al., 1997). Some of biofuel advantages are easy to adapt to other fuels, biodegradable, and environmentally friendly (Thanh et al., 2012). Its combustion produces better emissions compared to fossil fuels (Pattanaik and Misra, 2017), because it does not contain any pollutant compounds, such as: sulfur and nitrogen (Ramya et al., 2012).
Biofuel can be produced from vegetable oil through pyrolysis/thermal cracking (Xu et al., 2019; Fimberger et al., 2017), catalytic cracking (Li et al., 2018; Zhao et al., 2015; Ong and Bhatia, 2010), or plasma-assisted catalytic cracking (Istadi et al., 2019; Zhao et al., 2018; Gharibi et al., 2015; Hao et al., 2015). The most favorable vegetable oil, which is used as raw material for biofuel production, is palm oil (Istadi et al., 2019; Bhatia et al., 2009), because it has a relatively equal ratio of saturated and unsaturated oil (Pande et al., 2012). It has been reported that the vegetable oil types have no significant effect on liquid product yield (Buzetzki et al., 2011). However, the ratio of saturated and unsaturated oil has a significant effect on aromatic compounds in the liquid product (Beims et al., 2018).

The most developed cracking technology for vegetable oil conversion into biofuel is catalytic cracking which is due to low energy requirement, low operational cost, and high flexibility to utilize many vegetable oil types (Demirbas, 2009). Moreover, the catalytic cracking produces many kinds of products, such as: gas, organic liquid product (OLP), water, and coke (Ong and Bhatia, 2010). The temperature required for catalytic cracking is around $450{ }^{\circ} \mathrm{C}$, which is lower than pyrolysis or thermal

\footnotetext{
* Corresponding author: istadi@live.undip.ac.id
} 
cracking which required higher temperatures, usually at a range of $500-850{ }^{\circ} \mathrm{C}(\mathrm{Li}$ et al., 2009).

Another current developed cracking technology is plasma-assisted cracking, with or without the catalyst presence. The most favorable thing of plasma role is the cracking process over plasma reactor did not affected by the impurities (Jahanmiri et al., 2012). The sulfur compounds in the feedstock could be transformed into solid phase which is a unique possibility to remove sulfur compounds as the impurity (Wako et al., 2018). Jahanmiri et al. (2012) investigated a nanosecond pulsed dielectric barrier discharge plasma reactor for the conversion of heavy naphtha. Fan et al. (2019) compared the configurations of the plasma-catalytic system. Other researchers investigated the non-thermal or cold plasma for vegetable oil pyrolysis and heavy oil upgrading (Meeprasertsagool et al., 2017; Hao et al., 2015). The performance of conventional catalytic cracking was compared with plasma-assisted reactor for the conversion of palm oil into biofuel at different temperatures (Istadi $e t$ al., 2019). He said that the high energetics electron from the plasma can improve the reactor performance even the hybrid plasma-catalytic reactor which was carried out at lower temperature than the conventional reactor. However, the effect of temperature on plasma-assisted reactor for catalytic cracking has not been clear. Therefore, this study was focused on the effect of temperature on plasma-assisted reactor for cracking of palm oil into biofuels. The components distribution in the liquid product was also studied.

\section{Materials and Methods}

\subsection{Materials}

A commercial refined palm oil purchased from local market was used as the feedstock of cracking process. This research used the refined palm oil (not crude palm oil) was because it only focused on the performance of plasmaassisted reactor (not process development). The catalyst used in this study was the spent residue fluid catalytic cracking (RFCC) catalyst from petrochemical company in Indonesia. The nitrogen gas $(99.99 \%$, UHP) was used for flushing the tubing and reactor system before feeding process.

\subsection{Catalyst Preparation}

The spent RFCC catalyst was washed using distilled water at room temperature in order to remove the dirt. Then, the catalyst was dried at $120^{\circ} \mathrm{C}$ for 12 hours in an electric oven (Memmert). After the drying process, the catalyst was calcined at $550{ }^{\circ} \mathrm{C}$ for 4 hours in an electric box furnace (Ney Vulcan 3-550). The calcined catalyst powder was then pelleted and crushed into a diameter of $1.00-1.18 \mathrm{~mm}$. This spent RFCC catalyst used in this research was not modified.

\subsection{Reactor Performance Testing}

The experimental setup is shown in Figure 1. An electric furnace equipped with a temperature controller was used to adjust the temperature of reactor. Five grams of the spent RFCC catalysts were put into the discharge zone of the tubular glass reactor. In order to provide the high voltage on the reactor, a high voltage power supply with power up to 250 Watt $(50 \mathrm{kV} \mathrm{DC})$ was used. The discharge voltage during the reaction was measured using a High Voltage Probe and a digital multi-meter (Sanwa).

In order to eliminate the presence of oxygen, the reactor was flushed by nitrogen gas flow (100 $\left.\mathrm{cm}^{3} / \mathrm{min}\right)$ for 15 minutes before the reaction. The reactor was heated up to a temperature of 400,450 , and $500{ }^{\circ} \mathrm{C}$. After the targeted reactor temperature was reached, palm oil as a reactant was pumped by peristaltic pump at Weight Hourly Space Velocity (WHSV) of $2 \mathrm{~min}^{-1}$. The vapor product was condensed through a condenser in order to get the liquid fuel product and thus stored in a flask and analysed using a gas chromatography-mass spectrometry (GC-MS).

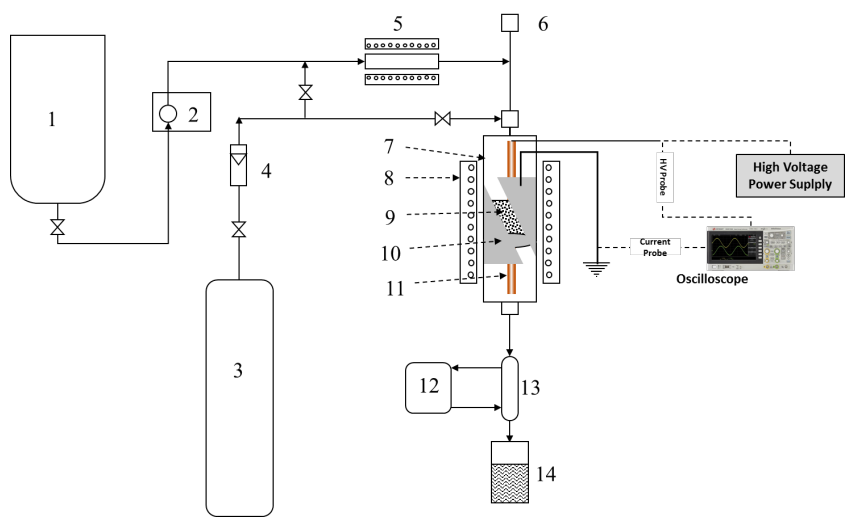

Fig. 1 Plasma-assisted reactor system for cracking of palm oil into biofuel: (1) Palm oil tank, (2) Peristaltic pump, (3) Nitrogen tank $\left(\mathrm{N}_{2}\right)$, (4) Rotameter-type flowmeter, (5) Electric preheater, (6) Thermocouple, (7) Reactor, (8) Electric heater, (9) Catalyst bed, (10) Ground electrode, (11) High voltage electrode, (12) Chiller, (13) Condenser, (14) Product collector.

\subsection{Fuels Product Analysis}

Gas Chromatography-Mass Spectrometry (GC-MS) (QP2010S SHIMADZU, DB-1 column) was used to identify the fuel product in order to determine the components of fuel product. The steady-state mass balance was used to derive the equations for calculating the conversion and selectivity at certain length time basis.

$$
\begin{aligned}
& \text { Conversion }(\%)=\frac{m_{\text {feed }}-m_{\text {unreacted palm oil }}}{m_{\text {feed }}} \times 100 \% \\
& \text { Selectivity of gasoline }(\%)=\frac{m_{\text {gasoline }\left(C_{5}-C_{12}\right)}}{m_{\text {feed }}-m_{\text {unreacted palm oil }}} \times 100 \% \\
& \text { Selectivity of kerosene }(\%)=\frac{m_{\text {kerosene }\left(C_{13}-C_{15}\right)}}{m_{\text {feed }}-m_{\text {unreacted palm oil }}} \times 100 \%
\end{aligned}
$$

Selectivity of diesel $(\%)=\frac{m_{\text {kerosene }\left(C_{16}-C_{18}\right)}}{m_{\text {feed }}-m_{\text {unreacted palm oil }}} \times 100 \%$

where $m_{\text {feed }}$ is equal to mass of palm oil fed to the reactor and $m_{\text {unreacted palm oil }}$ is mass of unreacted palm oil. 


\section{Result and Discussion}

\subsection{Comparison of Plasma-Assisted Catalytic Reactor and Conventional Catalytic Fixed Bed Reactor for Palm Oil Cracking}

In order to compare between performance of plasmaassisted reactor and conventional fixed bed reactor for palm oil cracking, the cracking process was conducted at $450{ }^{\circ} \mathrm{C}$ in the presence of the spent RFCC catalyst. The performance of conventional and plasma-assisted reactor at $450{ }^{\circ} \mathrm{C}$ is given in Table 1.

Table 1

The performance of conventional fixed bed and plasma-assisted reactors at $450{ }^{\circ} \mathrm{C}$

\begin{tabular}{lcc}
\hline \multicolumn{1}{c}{ Parameters } & $\begin{array}{c}\text { Conventional } \\
\text { fixed bed reactor }\end{array}$ & $\begin{array}{c}\text { Plasma-assisted } \\
\text { reactor }\end{array}$ \\
\hline Palm Oil Conversion (\%) & 99.08 & 99.02 \\
Selectivity of Gasoline (\%) & 12.07 & 16.43 \\
Selectivity of Kerosene (\%) & 39.07 & 52.74 \\
Selectivity of Diesel (\%) & 45.11 & 21.25 \\
\hline
\end{tabular}

Based on Table 1, presence of plasma can improve the reactor performance on catalytic cracking reaction of palm oil to fuels. The selectivity of gasoline and kerosene over plasma-assisted reactor are $16.43 \%$ and $52.74 \%$, respectively, which are higher than the selectivity over conventional fixed bed reactor $(12.07 \%$ and $39.07 \%$, respectively). However, the presence of plasma can decrease the selectivity of diesel and it was directed to lower chain hydrocarbons (gasoline/kerosene) due to role of plasma assistance. Therefore, the plasma has role on improving selectivity towards shorter-chain hydrocarbons product due to assisting the cracking reaction on the catalyst surface (excited electrons pair of covalent bond in carbon to carbon bonds). This shows that plasma influences reactions through collisions of high energetic electrons and the electrons pair on covalent bonds of reactant molecules of hydrocarbons or triglyceride (Istadi et al., 2019; Meeprasertsagool et al., 2017; Wu et al., 2015; Hao et al., 2015; Istadi and Amin, 2006). The plasma reactor technology utilized the high energetic electrons to assist breaking chemical bonds in hydrocarbon chains, so that the cracking occurs faster. The plasma reactors can damage the structure of carbon to carbon bonds and combine with role of catalytic surface reaction so that the desired hydrocarbon products can be achieved with lower energy and the resulting higher selectivity toward lower hydrocarbons (Istadi and Amin, 2006). Plasma discharge brings high energetic electrons (from high voltage power supply) that can assist breaking $\mathrm{C}-\mathrm{C}$ and $\mathrm{C}-\mathrm{H}$ bonds on the catalyst surface through the collision with reactant molecule. This collision leads to produce the small activated radicals which could be recombined and produce short-chain hydrocarbons (Jahanmiri et al., 2012) or assists on enhancing excitation of electrons pair of covalent bond in carbon to carbon bond of triglyceride which in turn lower energy required to break the bonds.

\subsection{Effect of Reactor Temperature on Plasma-Assisted Catalytic Reactor Performance for Palm Oil Cracking}

Reactor temperature is one of the most important parameters influencing the reactions performance in conventional chemical reactions due to the thermodynamic equilibrium limitation (Istadi, 2009). In order to study the temperature dependence of plasmaassisted catalytic cracking of palm oil, the plasma-assisted cracking process was conducted at reactor temperature of 400,450 , and $500^{\circ} \mathrm{C}$ (Table 2). Based on Table 2, as the increase of reactor temperature, the short-chain hydrocarbon product produced increases. The increase in reactor temperature resulted in more cutting of $\mathrm{C}$ bonds in the raw material, so that the percent of gasoline fractions that have the shortest $\mathrm{C}$ bonds increased (Hew et al., 2010). The higher the temperature, the greater the energy produced for cracking long-chain hydrocarbons into short-chain hydrocarbons. It is suggested that synergistic role of high energetic electrons from plasma and catalytic roles enhance the performance of the plasma-assisted catalytic cracking reactor. Saleem et al. (2019) reported that, on non-thermal plasma hydrocracking of toluene to lower hydrocarbons in a dielectric barrier discharge reactor, the selectivity of low hydrocarbons increases with increasing temperature.

Table 2

Effect of reactor temperature on the plasma-assisted catalytic cracking of palm oil

\begin{tabular}{|c|c|c|c|}
\hline \multirow{2}{*}{ Parameters } & \multicolumn{3}{|c|}{ Reactor Temperature $\left({ }^{\circ} \mathrm{C}\right)$} \\
\hline & 400 & 450 & 500 \\
\hline Palm Oil Conversion (\%) & 99.00 & 99.02 & 99.05 \\
\hline Selectivity of Gasoline (\%) & 21.01 & 16.43 & 28.08 \\
\hline Selectivity of Kerosene (\%) & 23.76 & 52.74 & 42.82 \\
\hline Selectivity of Diesel (\%) & 31.00 & 21.25 & 22.14 \\
\hline
\end{tabular}

As can be seen in Table 2, the selectivity of the shortestchain hydrocarbon component (gasoline) decreases from $21.01 \%$ to $16.43 \%$ as the increase of cracking temperature from $400{ }^{\circ} \mathrm{C}$ to $450{ }^{\circ} \mathrm{C}$. Then, it increases to $28.08 \%$ at cracking temperature of $500{ }^{\circ} \mathrm{C}$. Meanwhile, the fuels product distribution at different temperature was also different. At $400{ }^{\circ} \mathrm{C}$, the long-chain and short-chain hydrocarbon product distribution is relatively equal. On the other hand, at 450 and $500{ }^{\circ} \mathrm{C}$, the short-chain hydrocarbon product dominates the composition. It is suggested that the catalyst has not active at lower temperature, but the plasma plays as the main energy role for cracking process after the thermal energy by the reactor temperature. The collision of high-energetic electrons with reactant molecules converts the reactant molecules into hydrocarbon products. The energy provided by energetic electrons from plasma can assist on breaking the carbon to carbon bonds or at least excite the electron pairs of the covalent bonds (Istadi et al., 2019) then produce the short-chain hydrocarbons or produced radical molecules. Higher reaction temperature can be attributed to the opening up of the catalyst sites leading to more available active sites of the catalyst (Wako et al., 2018). Therefore, the catalyst can direct the cracking product into shorter-chain hydrocarbons. The possible formation of radicals produced by the collision of high-energetic electrons and reactant molecules was then directed into short-chain hydrocarbons product. Pietruszka and Heintze (2004) reported that the catalyst became active and contributed to the reaction activity with synergistic effect between plasma discharge and catalysis at higher 
temperatures, but role of plasma was more dominant than the reactor temperature (Buchori et al., 2016).

\subsection{Effect of Reactor Temperature on Components Composition Distribution in Liquid Fuels Product}

The liquid fuels product components distribution of palm oil cracking process over plasma-assisted catalytic reactor is also studied. The study is focused on the effect of reactor temperature on liquid fuels components distribution which were analysed using GC-MS method. The main fuel components are hydrocarbons, aromatic, and oxygenated compounds. The hydrocarbon components mainly contain paraffin and olefin. The authors suggest that the components distribution of liquid fuel product depends on the reactor temperature.

Hydrocarbon compounds in the liquid fuel product are total paraffins and olefins presence. The hydrocarbon compound distribution in the liquid product of palm oil cracking process over plasma-assisted reactor at different reactor temperatures is provided in Figure 2. It can be seen that the hydrocarbons composition (paraffin and olefin) decreases as increasing reactor temperature.

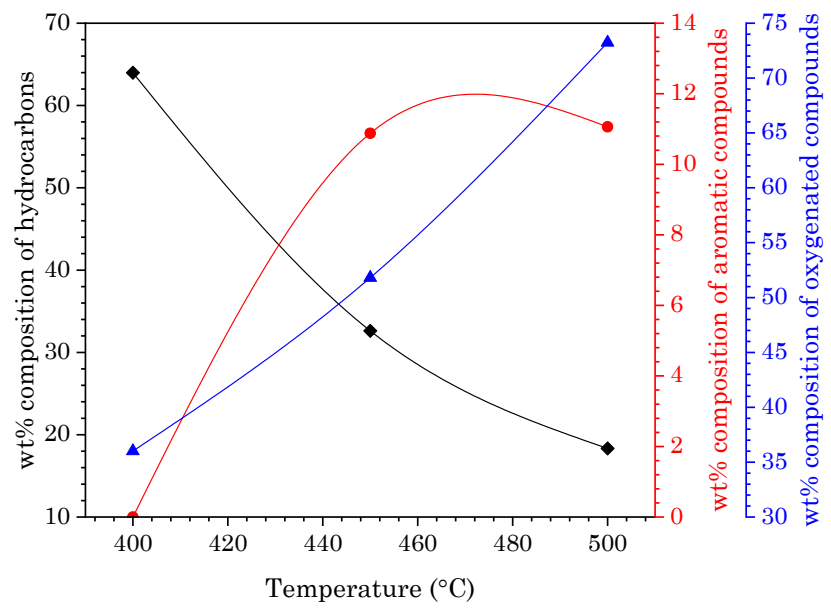

Fig. 2 Components distribution in the liquid fuels product at different reactor temperature

The decreased paraffins and olefins (hydrocarbons) compounds is affected by the side reactions that occurred. Doronin et al. (2013) said that in the catalytic cracking reaction, several reactions can occur, such as: cracking, aromatization, isomerization, oligomerization, deoxygenation, alkylation, and polymerization. The energy provided by plasma can assist breaking the bonds or can excite the electron pairs of the carbon to carbon covalent bonds (Istadi et al., 2019) then produce the shortchain hydrocarbons or even produce radicals. The molecules are then converted into other products via those reaction pathways.

Increasing the reactor temperature affects on the more active catalyst as reported by Wako et al. (2018) which in turn many reaction pathways can occur at high temperatures. As a result, the short-chain hydrocarbon and radical molecules produced by the collisions of high energetic electrons with reactant molecules are converted into many products, such as: paraffins, olefins, and other compounds. The paraffins and olefins molecules can also be converted into other side products, such as: aromatic and oxygenated compounds.

The aromatic compound composition distribution in the liquid fuels product of palm oil cracking process over plasma-assisted reactor at different reactor temperatures is provided in Figure 2. From Figure 2, the aromatic compounds content increases with reactor temperature. However, the aromatic compound was not detected in the liquid fuels product when the reactor operated at $400{ }^{\circ} \mathrm{C}$, but only appeared when it operated at 450 and $500{ }^{\circ} \mathrm{C}$. The aromatic compound composition resulted at 450 and 500 ${ }^{\circ} \mathrm{C}$ is $10.88 \%$ and $11.06 \%$, respectively. It is suggested that the aromatic compound contented in liquid fuel product is slightly increased as the increasing reactor temperature.

The increasing aromatic compounds content in the liquid fuels product is contributed by role of the reactor temperature causing enhancement of catalyst surface reaction activity. This fact confirms that the catalyst leads to aromatization reaction due to possibility of cyclization and aromatization reaction occurred. In the cracking process, those reactions can be accelerated by the increase of reactor temperature as suggested by previous researcher ( $\mathrm{Li}$ et al., 2018). The formation of aromatic compound is also affected by the surface catalytic activity (Chen et al., 2015) which is also assisted by plasma role on breaking the covalent bonds or at least excite the electron pairs of the covalent bonds (Istadi et al., 2019) to produce the shorter-chain hydrocarbons. The other hydrocarbons product, paraffins and olefins, can also be converted into cycloalkanes and then converted into aromatic compound by the catalyst (Chen et al., 2015; Doronin et al., 2013). Therefore, the increased catalyst activity leads to increasing the aromatic compound. The higher reaction temperature can be attributed to the opening up of the catalyst sites leading to more available active sites of the catalyst (Wako et al., 2018) which in turn favouring the aromatic compound production.

The oxygenated compounds present in the liquid product are alcohol, ketone, aldehyde and ester. The oxygenated compounds distribution in the liquid product of palm oil cracking process over plasma-assisted reactor at different reactor temperatures is provided in Figure 2. As can be seen in Figure 2, the oxygenated compounds increase as the increase of reactor temperature.

The oxygenated molecules were also present in the liquid fuels product which come from fatty acid groups as the main components in palm oil. The detected oxygenated compound in the liquid fuels product confirms that the catalyst used does not favour for deoxygenation reaction, even the plasma role cannot effectively break the oxygen bond in the fatty acid groups.

\section{Conclusion}

In this study, the effects of reactor temperature and plasma role on the catalytic cracking were studied. The presence of plasma (high energetic electrons) can increase the selectivity to shorter-chain hydrocarbons product due to the collisions of high-energetic electrons from plasma and electrons pair of covalent carbon-carbon bonds of reactant molecules (triglyceride). The high energetic electrons generated by plasma can break the reactant molecule or can assist the surface catalytic reaction by exciting the electron pairs of covalent bonds. Indeed, the 
synergistic role of high-energetic electrons from plasma and catalytic roles on the catalyst surface enhances the performance of the catalytic cracking reactor, while the increasing reactor temperature favours the selectivity to shorter-chain hydrocarbon products. However, the increasing reactor temperature leads to the formation of aromatic and oxygenated compounds in the liquid fuels product.

\section{Acknowledgments}

The authors would like to express their sincere gratitude's to the Research Institution and Community Service, Diponegoro University, Semarang, Indonesia for the financial support received under the research project of Riset Publikasi Internasional Bereputasi Tinggi (RPIBT) with contract number: 38707/UN7.P4.3/PP/2018.

\section{References}

Beims, R.F., Botton, V., Ender, L., Scharf, D.R., Simionatto, E.L., Meier, H.F. and Wiggers, V.R. (2018) Effect of degree of triglyceride unsaturation on aromatics content in bio-oil. Fuel, 217, 175-184.

Bhatia, S., Mohamed, A.R. and Shah, N.A.A. (2009) Composites as cracking catalysts in the production of biofuel from palm oil: Deactivation studies. Chemical Engineering Journal, 155(1-2), 347-354.

Buchori, L., Istadi, I., Purwanto, P., Kurniawan, A. and Maulana, T.I. (2016) Preliminary testing of hybrid catalytic-plasma reactor for biodiesel production using modified-carbon catalyst. Bulletin of Chemical Reaction Engineering and Catalysis, 11(1), 59-65.

Buzetzki, E., Sidorová, K., Cvengrošová, Z. and Cvengroš, J. (2011) Effects of oil type on products obtained by cracking of oils and fats. Fuel Processing Technology, 92(10), 20412047.

Chen, H., Wang, Q., Zhang, X. and Wang, L. (2015) Quantitative conversion of triglycerides to hydrocarbons over hierarchical ZSM-5 catalyst. Applied Catalysis B: Environmental, 166-167, 327-334.

Demirbas, A. (2009) Progress and recent trends in biodiesel fuels. Energy Conversion and Management, 50(1), 14-34.

Doronin, V.P., Potapenko, O. V., Lipin, P. V. and Sorokina, T.P. (2013) Catalytic cracking of vegetable oils and vacuum gas oil. Fuel, 106, 757-765.

Fan, Y., Xiong, Y., Zhu, L., Fan, L., Jin, L., Chen, Y. and Zhao, W. (2019) Comparison of the one-step and two-step plasmacatalytic upgrading of biomass pyrolysis volatiles to biofuel. Chemical Engineering and Processing - Process Intensification, 135, 53-62.

Fimberger, J., Swoboda, M. and Reichhold, A. (2017) Thermal cracking of canola oil in a continuously operating pilot plant. Powder Technology, 316, 535-541.

Gharibi, M., Khosravi, A., Khani, M.R., Shahabi, S.S., Guy, E.D. and Shokri, B. (2015) Dielectric barrier discharge plasma torch treatment of pyrolysis fuel oil in presence of methane and ethane. Journal of Electrostatics, 76, 178-187.

Giampietro, M., Ulgiati, S. and Pimentel, D. (1997) Feasibility of Large-Scale Biofuel Production. BioScience, 47(9), 587600.

Hao, H., Wu, B.S., Yang, J., Guo, Q., Yang, Y. and Li, Y.W. (2015) Non-thermal plasma enhanced heavy oil upgrading. Fuel, 149, 162-173.

Hew, K.L., Tamidi, A.M., Yusup, S., Lee, K.T. and Ahmad, M.M. (2010) Catalytic cracking of bio-oil to organic liquid product (OLP). Bioresource Technology, 101(22), 8855-8858.

Istadi, I. (2009) Hybrid Catalytic-Plasma Reactor Development for Energy Conversion. Semarang, Badan Penerbit
Universitas Diponegoro.

Istadi, I. and Amin, N.A.S. (2006) Co-generation of synthesis gas and $\mathrm{C}_{2+}$ hydrocarbons from methane and carbon dioxide in a hybrid catalytic-plasma reactor: A review. Fuel, 85(5-6), $577-592$.

Istadi, I., Buchori, L., Anggoro, D.D., Riyanto, T., Indriana, A., Khotimah, C. and Setiawan, F.A.P. (2019) Effects of Ion Exchange Process on Catalyst Activity and PlasmaAssisted Reactor Toward Cracking of Palm Oil into Biofuels. Bulletin of Chemical Reaction Engineering \& Catalysis, 14(2), 459-467.

Jahanmiri, A., Rahimpour, M.R., Mohamadzadeh Shirazi, M., Hooshmand, N. and Taghvaei, H. (2012) Naphtha cracking through a pulsed DBD plasma reactor: Effect of applied voltage, pulse repetition frequency and electrode material. Chemical Engineering Journal, 191, 416-425.

Li, C., Ma, J., Xiao, Z., Hector, S.B., Liu, R., Zuo, S., Xie, X., Zhang, A., Wu, H. and Liu, Q. (2018) Catalytic cracking of Swida wilsoniana oil for hydrocarbon biofuel over $\mathrm{Cu}$ modified ZSM-5 zeolite. Fuel, 218, 59-66.

Li, F., Jiang, J., Liu, P., Zhai, Q., Wang, F., Hse, C.Y. and Xu, J. (2018) Catalytic cracking of triglycerides with a base catalyst and modification of pyrolytic oils for production of aviation fuels. Sustainable Energy and Fuels, 2(6), 12061215.

Li, H., Shen, B., Kabalu, J.C. and Nchare, M. (2009) Enhancing the production of biofuels from cottonseed oil by fixedfluidized bed catalytic cracking. Renewable Energy, 34(4), 1033-1039.

Meeprasertsagool, P., Watthanaphanit, A., Ueno, T., Saito, N. and Reubroycharoen, P. (2017) New insights into vegetable oil pyrolysis by cold plasma technique. Energy Procedia, 138, 1153-1158.

Ong, Y.K. and Bhatia, S. (2010) The current status and perspectives of biofuel production via catalytic cracking of edible and non-edible oils. Energy, 35(1), 111-119.

Pande, G., Akoh, C.C. and Lai, O.-M. (2012) Food Uses of Palm Oil and Its Components. In: O.-M. Lai, C.-P. Tan, \& C. C. Akoh eds. Palm Oil: Production, Processing, Characterization, and Uses. United States of America, AOCS Press., 561-586.

Pattanaik, B.P. and Misra, R.D. (2017) Effect of reaction pathway and operating parameters on the deoxygenation of vegetable oils to produce diesel range hydrocarbon fuels: A review. Renewable and Sustainable Energy Reviews, 73, $545-557$.

Pietruszka, B. and Heintze, M. (2004) Methane conversion at low temperature: the combined application of catalysis and non-equilibrium plasma. Catalysis Today, 90(1-2), 151158.

Ramya, G., Sudhakar, R., Joice, J.A.I., Ramakrishnan, R. and Sivakumar, T. (2012) Liquid hydrocarbon fuels from jatropha oil through catalytic cracking technology using AlMCM-41/ZSM-5 composite catalysts. Applied Catalysis A: General, 433-434, 170-178.

Saleem, F., Zhang, K. and Harvey, A. (2019) Temperature dependence of non-thermal plasma assisted hydrocracking of toluene to lower hydrocarbons in a dielectric barrier discharge reactor. Chemical Engineering Journal, 356, 1062-1069.

Thanh, L.T., Okitsu, K., Boi, L. V. and Maeda, Y. (2012) Catalytic Technologies for Biodiesel Fuel Production and Utilization of Glycerol: A Review. Catalysts, 2(1), 191-222.

Wako, F.M., Reshad, A.S., Bhalerao, M.S. and Goud, V. V. (2018) Catalytic cracking of waste cooking oil for biofuel production using zirconium oxide catalyst. Industrial Crops and Products, 118, 282-289.

Wu, A., Li, X., Chen, L., Zhu, F., Zhang, H., Du, C. and Yan, J. (2015) Utilization of waste rapeseed oil by rotating gliding arc plasma. International Journal of Hydrogen Energy, 40(30), 9039-9048.

Xu, L., Cheng, J.-H., Liu, P., Wang, Q., Xu, Z.-X., Liu, Q., Shen, J.-Y. and Wang, L.-J. (2019) Production of bio-fuel oil from 
Citation: Istadi, I., Riyanto, T., Buchori, L., Anggoro, D.D., Saputra, R.A., and Muhamad, T.G. (2020), Effect of Temperature on Plasma-Assisted Catalytic Cracking of Palm Oil into Biofuels. Int. Journal of Renewable Energy Development, 9(1),107-112, doi.org/10.14710/ijred.9.1.107-112

$\mathrm{P}$ a g e $\mid 112$

pyrolysis of plant acidified oil. Renewable Energy, 130, 910-919.

Zhao, W., Huang, J., Ni, K., Zhang, X., Lai, Z., Cai, Y. and Li, X. (2018) Research on Non-Thermal Plasma assisted HZSM5 online catalytic upgrading bio-oil. Journal of the Energy Institute, 91(4), 595-604.
Zhao, X., Wei, L., Cheng, S. and Julson, J. (2015) Optimization of catalytic cracking process for upgrading camelina oil to hydrocarbon biofuel. Industrial Crops and Products, 77, 516-526.

This article is an extended version of a paper presented at International Conference of Process and Product Engineering (ICCPPE 2019) held on Sept 25, 2019. The article has been reviewed by journal peer-reviewers including complete proofs.

c) (i) (C) 2020. This article is an open access article distributed under the terms and conditions of the Creative Commons Attribution (CC BY) license (http://creativecommons.org/licenses/by/4.0/) 